\title{
TRÊS VERSÕES DE ORFEU
}

\author{
Thaïs Flores Nogueira Diniz
}

UFMG

\begin{abstract}
RESU MO
Ao se analisarem três criações intertextuais cujo tema é o mito de Orfeu retratam-se três momentos da história brasileira, levando-se em conta elementos do mito e rubricas da peça que serviu de "origem" para os dois filmes. Conclui-se que não só a música e a arte brasileira são louvadas, mas também, através delas, a identidade nacional é retratada.
\end{abstract}

\section{PALAVRAS - CHAVE}

mito, Orfeu, Vinicius de Moraes, Marcel Camus, Carlos Diegues

Desde que Julia Kristeva criou o termo intertextualidade, este foi apropriado por quase todos os movimentos teóricos relativos à crítica das artes. Diz-se hoje que todas as criações artísticas são intertextuais, porque partem de sistemas e tradições oriundos de outros textos e culturas. As adaptações fílmicas, consideradas como traduções de outros textos - como romances, peças ou contos — também são criações intertextuais para cuja interpretação o leitor deve estabelecer relações entre os sistemas de signos literário e cinematográfico.

Este trabalho pretende interpretar obras relacionadas pelo tema, que dialogam entre si, pertencentes a três sistemas semióticos diferentes: o mítico, o literário e o cinematográfico. Como se sabe, o mito, ao lado de sua função narrativa, também representa os valores de um povo ou de uma sociedade. Segundo o mito clássico, Orfeu, músico virtuoso que seduzia a todos com seu canto, uniu-se à ninfa Eurídice. Perdeu-a, entretanto, quando a amada foi picada por uma cobra. Não podendo sobreviver à perda, Orfeu resolveu buscá-la nas

sombrias paragens onde habitam os corações que não se enterneceram com os rogos humanos (...) Abordando inexoravelmente o rei das sombras, Orfeu dele obteve o favor de retornar com Eurídice ao sol (...) com a condição de que não olhasse para trás a ver se a amada o seguia. Mas no justo instante em que iam ambos respirar o claro dia, a inquietude do amor perturbou o infeliz amante. Impaciente de ver Eurídice, Orfeu voltou-se. E com um só olhar que lhe dirigiu perdeu-a para sempre. ${ }^{1}$

Retomando o mito, com a preocupação de transpor a história para o contexto nacional, Vinicius atribuiu ao herói um sobrenome bem brasileiro: Orfeu da Conceição.

\footnotetext{
${ }^{1}$ Meunier. Excerto de La leyenda dorada de los dioses y de los héroes, citado em Moraes. Orfeu da Conceição, p. 399-400. As citações de Orfeu da Conceição, neste texto, serão assinaladas com as iniciais OC, acompanhadas do(s) número(s) da(s) páginas.
} 
Em novas re-apropriações, Marcel Camus (1959) e Carlos Diegues (1999) retomam a peça de Vinicius, adaptando-a para o cinema.

Nesta análise, pretende-se estabelecer a relação entre as três obras e o mito clássico e entre os vários sistemas de signos, levando-se em conta as perspectivas ideológicas e sociais implícitas no processo.

No nível semiótico, a investigação recai sobre os elementos que, em ambos os filmes, desempenham a mesma função exercida na peça de Vinicius de Moraes e no mito clássico, que evoca uma aspiração inerente ao ser humano: viver um amor eterno. Mesmo depois da morte, Orfeu e Eurídice permanecem unidos. Na peça, a intensidade da união é sinalizada por algumas rubricas:

A frase musical [do violão] correspondente ao nome de Eurídice reponta pungente em seu dedilhado agônico. [Orfeu] aproxima-se da amurada, voltado para as luzes da cidade. Uma lufada de vento traz sons como de uma harpa, que parecem enunciar o nome de Eurídice. Tudo é Eurídice na mecânica do instante, e a presença da mulher amada deve manter-se com uma força e fatalidade inenarráveis. (OC, p.408)

As indicações cênicas, com suas ressonâncias poéticas, funcionam ainda como uma introdução para a fala de Orfeu, que expressa o sentimento de ligação eterna à mulher amada:

ORFEU: Você não entende, não; não sou mais eu

É ele, minha mãe... Orfeu é Eurídice

A música de Orfeu é como o vento

E a flor; sem a flor não há perfume

Há o vento sozinho, e é triste o vento

Sozinho, minha mãe... (OC, p.407)

ORfeu: Eurídice, dizer

Que eu nasci antes de você nascer!

Como é que pode ser? o que é que eu era

Antes de Eurídice? Um feixe grande de ossos?

Um bocado de carne e pele escura?

Dois pés e duas mãos? E o sentimento

A idéia, o que eram? Nada! O nascimento

De Orfeu foi quando Eurídice nasceu! (OC, p.410)

Os dois filmes ratificam o arquétipo do amor eterno.

$\mathrm{Na}$ versão de Camus, durante os preparativos para um pretendido casamento com Mira (a namorada anterior), a jovem ingênua não apreende a referência irônica do juiz ao mito grego. Ao leitor não escapa a função do episódio, que é explicitar o processo de re-escrita empreendido pelo cineasta:

Juiz: Qual é o seu nome?

OrFEU: Orfeu.

Juiz: Orfeu... Orfeu... Ahh... Naturalmente a noiva se chama Eurídice.

MirA: O quê? Eu não me chamo Eurídice... Por que o senhor está dizendo isso?

Juiz: Porque Orfeu ama Eurídice, todo mundo sabe.

Mira: (para Orfeu) E você gosta de alguma Eurídice?

OrfEu: Eh? Eu lá conheço alguma Eurídice? Que história toda é essa?

Juzz: Nada... Nada... É uma velha história. Eu estava gracejando. 
Quando Orfeu vem finalmente a conhecer Eurídice, a amada definitiva, o encontro, revestido de um lirismo mágico, quase místico, atua como nova oportunidade de rememoração do mito:

Orfeu: Como é teu nome?

EURÍDICE: Eurídice.

Orfeu: Que maravilha! E eu que já gosto de você! Todo mundo sabe que Orfeu gosta de Eurídice, pois acabaram de me contar...

EuRídicE: E você é Orfeu?

Orfeu: Sim, da cabeça aos pés.

EURídicE: Mas eu não gosto de você.

Orfeu: Gosta sim. Lembra bem. Isto é mesmo uma velha história. Há mil, muitos mil anos atrás, Orfeu era triste e melancólico, como este passarinho preso na gaiola. Mas um dia, um dia, nas cordas de seu violão que só um amor procurou, ouviu... uma voz falar dos beijos perdidos nos lábios de Eurídice. E os lábios de Eurídice estavam trêmulos de ansiedade (...) e a flor perfumada de sua boca se entreabriu...

Orfeu tenta beijá-la e ela se esquiva

Orfeu: (exasperado) Não, você é brotinho demais, você não pode se lembrar...

EURídicE: Eu me lembro das palavras que você cantava.

ORFEU: Mas são as mesmas!

EURíDicE: Justamente. Mas era da melodia delas que eu gostava.

O filme de Carlos Diegues percorre uma trajetória narrativa semelhante, fazendo com que Orfeu (como Romeu com Rosalinda na peça shakespeariana) abandone a primeira namorada em favor de Eurídice, a amada mítica. No entanto, para o rompimento com Mira, utiliza, além do diálogo, também impregnado de lirismo, um recurso tipicamente cinematográfico, o corte.

Ouçamos a voz de Orfeu:

Sabia? Existem estrelas que já morreram há mais de dez milhões de anos luz, mas a gente fica vendo o brilho delas no céu. Daí eu fico pensando: deve ter alguma estrela que já nasceu, brilha muito mais que todas as outras juntas, mas a gente não sabe, porque luz delas ainda não chegou até aqui.

Segue-se o corte, quando a imagem de Eurídice aparece refletida no vidro traseiro de um táxi, assinalando a transição do antigo para o novo objeto de amor.

Os exemplos ilustram a integração do mítico, do literário e do fílmico no produto final exibido ao público. Entretanto outros fatores convidam a uma análise dos textos envolvidos, tendo em vista sua localização em contextos e circunstâncias diversas.

Vinicius de Moraes substitui o local inicial, o Monte Olimpo, morada dos deuses, por um morro carioca, morada de Orfeu. O tom poético da descrição do cenário carioca sugere que a peça parece mais destinada à leitura que à encenação.

O morro, a cavaleiro da cidade, cujas luzes brilham ao longe. Platô de terra com casario ao fundo, junto ao barranco, defendido, à esquerda, por pequena amurada de pedra, em semicírculo, da qual desce um lance de degraus. Noite de lua, estática, perfeita. No barraco de Orfeu, ao centro, bruxuleiam lamparinas. Ao levantar o pano, a cena é deserta. Depois de prolongado silêncio, começa-se a ouvir, distante, o som de um violão plangendo uma valsa que pouco a pouco se aproxima, num tocar divino, simples e direto como uma fala de amor. (OC, p.402) 
Camus e Diegues também usam o morro e a favela como cenários; entretanto, incorporam muitos significados ausentes da descrição de Vinicius. Os filmes também substituem a descrição poética por imagens, estereotipadas ou realistas.

A favela descrita por Camus transmite o estereótipo do Brasil como o país do Carnaval, de mulheres que dançam enquanto sobem o morro com latas de água na cabeça, de negociantes que vendem fiado tomando como garantia os beijos das mulatas... Segundo Antônio Callado, essa visão folclórica foi muito criticada por Godard. Segundo Marcelo Castilho de Avellar, a visão idílica da favela seria mais adequada às campinas das árcades da Grécia antiga do que à do Rio de Janeiro do século XX. Porém, o filme de Diegues, com sua favela construída cinematograficamente, é mais fiel à realidade e cultura brasileiras, tendo o mérito da contemporaneidade e de relacionar-se com a identidade nacional. O filme se desenrola como uma reportagem de TV, num ambiente marcado pelo tráfico de drogas, execuções, violência policial, enquanto inocentes moradores morrem atingidos por balas perdidas.

Do ponto de vista temporal também diverge a descrição da favela nas três obras, que retratam momentos diferentes em nossa história. Para Vinicius o morro se apresenta como um local idílico, palco para o desenrolar de uma história triste, para ele "uma tragédia carioca". Para Marcel Camus, o cenário mostra a imagem do Brasil no exterior nos anos sessenta: o país do Carnaval. Nada ocorre de trágico na história contada por Camus, motivada por um acidente. Já o cenário contemporâneo de Carlos Diegues expressa o drama dos marginalizados das grandes cidades, obrigados a conviver de perto com o tráfico de drogas, os tiroteios e a truculência policial, num país muito mais violento que o Brasil dos anos sessenta.

A preocupação de Vinicius de Moraes em traduzir o mito grego para o nosso contexto se materializa também através de outros elementos, além do cenário. Uma de suas primeiras recomendações, em nota à Introdução da peça, refere-se aos atores. "Todas as personagens da tragédia devem ser normalmente representadas por atores da raça negra, (...) podendo eventualmente ser encenada com atores brancos." (OC, p.400) Antônio Callado afirma que, ao lançar a peça, Vinicius a apresentara como uma homenagem ao negro brasileiro, pelo muito que já dera ao Brasil. (OC, p.5-12) Como se sabe, a população das favelas do Rio não é composta apenas por pessoas negras. Portanto a exigência de atores negros não indica apenas a "naturalização" do contexto grego para o brasileiro nem simples homenagem aos escravos negros, podendo sinalizar resistência contra o racismo, considerando-se, entre outros fatores, a data da peça: 1956, pouco depois da publicação de "Reflexões sobre o racismo", de JeanPaul Sartre. A interpretação dada por Vinicius sugere que o Orfeu Negro, através de seu encanto e sedução, visa a recuperar em Eurídice a identidade negra perdida. No contexto de 1956, essa interpretação é plenamente satisfatória.

Os filmes de Camus e Diegues divergem da peça, introduzindo personagens que não são negras. Eurídice é mulata no primeiro — "roxinha" - e mestiça "indiazinha do Acre" - no segundo. Ao usarem personagens híbridos em suas versões,

\footnotetext{
${ }^{2}$ Os termos transliterar e naturalizar, criados por Lefevere, referem-se aos procedimentos usados respectivamente para criar imagens exóticas, conservando-as próximas à cultura estrangeira ou para amenizar a obra, modificando-a, para torná-la próxima à cultura receptora.
} 
esses dois cineastas talvez nem estivessem pensando em homenagear escravos ou fazer resistência ao racismo. A mulata de Camus poderia estar apenas representando o nosso povo, já que a mulata é considerada o tipo da mulher brasileira sensual. Diegues, por sua vez, poderia estar, sim, denunciando o descaso do governo e da sociedade em geral em relação ao problema do índio, mas mais diretamente a violência e a pobreza a que está sujeito o nosso povo, reconhecidamente mestiço.

Sabe-se que em nossa sociedade em geral, mas principalmente nas classes menos favorecidas, sujeitas a maior violência, vive-se continuamente entre a vida e a morte. Essa oposição vida/morte, corporificada pela dupla morte de Eurídice, primeiro picada por uma cobra e depois como punição a Orfeu pela sua desobediência, é um dos temas recorrentes no mito de Orfeu. Na peça de Vinicius, Orfeu parece pressentir a morte da jovem, tal o medo de perdê-la. E o conflito morte/vida emerge na discussão entre Orfeu e a morte, encarnada pela Dama Negra:

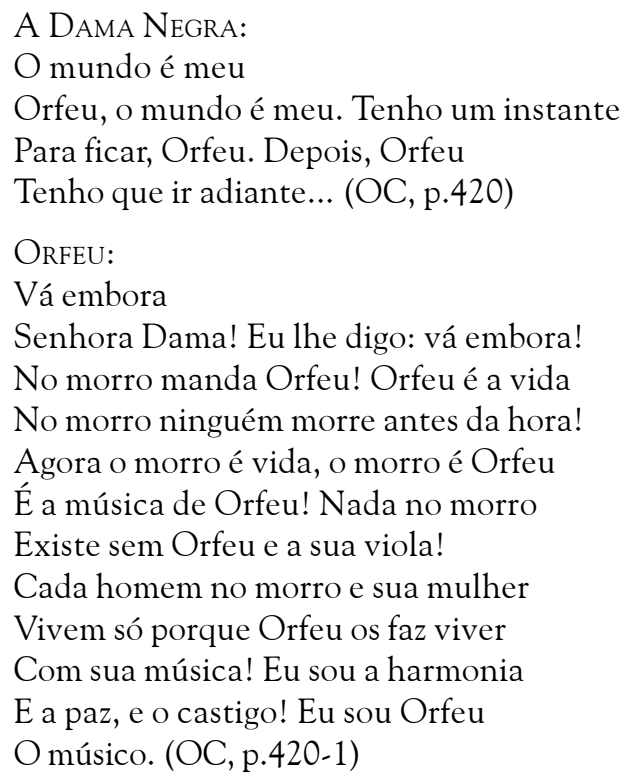

No episódio seguinte, o escurecimento da cena, exigido pela rubrica, assinala a substituição da Dama Negra por Eurídice, personagem que passa a incorporar a morte:

ORFEU: (a voz estrangulada)

Não é nem mais querer... é coisa ruim

É morte!

EuRíDice: (pensativa)

Morte? Morrer... E se eu morresse?

ORFEU: (num soluço)

Cala a boca, querida! Se eu

Te perdesse eu iria te buscar

Fosse no Inferno, tanto que te quero!

(OC, p.423)

ORFEU: (beija-a)

Adeus!

[Orfeu] entra. Ao voltar-se Eurídice, Aristeu, surgindo do escuro, um punhal na mão, mataa espetacularmente. Eurídice cai. (OC, p.426) 
EURÍDICE: (ao morrer)

Adeus.

ARISTEU: (fugindo embuçado)

Adeus, mulher de Orfeu!

A cena vai escurecendo lentamente, enquanto a Dama Negra surge do canto onde se ocultara. Tudo é silêncio. Com um gesto largo a Dama Negra tira o grande manto que a veste e cobre com ele o corpo de Eurídice morta enquanto cai o pano. (OC, p.427)

O filme de Camus transforma a Dama Negra de Vinicius em um folião fantasiado de morte. Sua identidade é uma incógnita, mas o folião persegue Eurídice, parecendo determinado a matá-la. O leitor fica em dúvida: seria uma pessoa real ou apenas um produto da imaginação? O fato é que, ao fugir de seu perseguidor, a moça é eletrocutada num fio de alta tensão.

No filme de Carlos Diegues, a morte de Eurídice representa um acontecimento quase corriqueiro. A bala assassina, disparada por Lucindo, rei do tráfico de drogas da favela, antigo amigo de Orfeu, resvala numa pedra antes de atingir a moça. Supõese que o traficante não teria intenção de matá-la, mas, dopado como estava, não teve a coragem de levá-la a um hospital, o que implicaria enfrentar a polícia. Agonizante, a jovem foi atirada a um local de "desova" de corpos da quadrilha de traficantes. $\mathrm{Na}$ cena do filme, o local simboliza o inferno, indicado, um tanto artificialmente, pela presença de cobras, esqueletos, cadáveres, lixo, onde Orfeu teria de descer para recuperá-la.

Com sua rede de ligações intertextuais, os textos estudados constituem obras independentes, novas e criativas, marcadas pelos inevitáveis traços culturais próprios de cada versão. O filme de Diegues incorpora a tristeza do mito. Apesar disso, apresenta o aspecto festivo de louvor à música nacional. Celebram-se assim os músicos dispersos pelos ambientes populares de morros, favelas e bares.

Usando sua arte para celebrar a paixão e o amor latinos, em belíssimas canções compostas especialmente para a peça, Vinicius torna-se, para nós, o verdadeiro Orfeu. Tanto Camus como Diegues, ao usarem essas canções em seus filmes, estariam também prestando uma homenagem ao autor da peça e a outros poetas, como Caetano Veloso, cuja música é incluída no filme de Diegues. Através de todos esses Orfeus exalta-se nossa arte.

Coro:

Juntaram-se a Mulher, a Morte e a Lua

Para matar Orfeu, com tanta sorte

Que mataram Orfeu, a alma da rua

Orfeu o generoso, Orfeu, o forte.

Porém as três não sabem de uma coisa:

Para matar Orfeu não basta a Morte.

Tudo morre que nasce e que viveu

Só não morre no mundo a voz de Orfeu.

Circulando entre tantos textos cultural ou semioticamente inter-relacionados, procuramos encontrar um sentido na referência ao mito de Orfeu. Reescrito no presente, o mito conserva os elementos clássicos, principalmente a crença no poder sedutor da arte, agregando-lhes dados atuais de produção ou de leitura. Os filmes, obras 
contemporâneas, buscam compensar o sentimento de incerteza próprio do momento, sem deixar de celebrar a imortalidade da arte, especialmente da arte popular.

Ao transformarem Orfeu, membro das camadas negras e oprimidas da população, numa representação da música popular brasileira, os filmes oferecem mais uma possibilidade de leitura: celebram não apenas a música popular (vista por Mário de Andrade como nossa criação mais típica e vigorosa) mas a própria identidade nacional. Nesse sentido, os filmes acenam para a visão de José Miguel Wisnik, endossada por Silviano Santiago: a música popular brasileira constitui o espaço "onde se articulam, são avaliadas e interpretadas as contradições sócio-econômicas e sociais do país, dandonos portanto seu mais fiel retrato". ${ }^{3}$

A)

\title{
A B STRACT
}

On analysing three intertextual texts on the theme of the Orpheus myth, this paper argues that they project three moments in Brazilian history. Some elements of the myth and some stage directions by the author of the play that served as "origin" of the other two films are taken into consideration. The conclusion is that not only Brazilian art and music are praised, but, through them, national identity is portrayed.

\section{KEY-WORDS}

myth, Orpheus, Vinicius de Moraes, Marcel Camus, Carlos Diegues

\author{
* Agradeço as valiosas sugestões das colegas \\ Prof. Dra. Solange Ribeiro de Oliveira e \\ Prof. Dra. Lúcia Helena Azevedo Vilela.
}

${ }^{3}$ SAntiago. Democratização no Brasil - 1979-1981 (Cultura versus arte), p.19. 


\section{REFERÊNCIAS BIBLIOGRÁFICAS}

Avellar, Marcello Castilho de. Orfeu mergulha de volta ao inferno. In: Estado de Minas, Espetáculo, p.6, 14 abr. 1999.

Callado, Antônio. Orfeu tirou Tom do piano e Vinicius do país. In: Folha de S.Paulo, Ilustrada, p.5-12, 30 set. 1995.

Camus, Marcel (dir). Orfeu Negro. França, 1959.

Diegues, Carlos (dir). Orfeu. Brasil, 1999.

Lefevere, Andre. Translating literature: Practice and theory in a comparative literature context. New York: The Modern Language Association of America, 1992.

Moraes, Vinicius de. Orfeu da Conceição: uma tragédia carioca. In: Poesia Completa e Prosa. Rio de Janeiro: Editora Nova Aguilar, 1987.

Santiago, Silviano. Democratização no Brasil - 1979-1981 (Cultura versus arte). In: Antello, Raul et alii (org.). Declínio da Arte. Ascenção da Cultura. Florianópolis: Obra Jurídica, 1998. p.11-23.

SARTRE, Jean-Paul. Reflexões sobre o racismo. Trad. J. Guinsberg. [s.l.]: Difusão Européia do Livro, 1963. 